\title{
Proliferation and Differentiation of Goat Bone Marrow Stromal Cells in 3D Scaffolds With Tunable Hydrophilicity
}

\author{
J. L. Escobar Ivirico, ${ }^{1,2}$ M. Salmerón-Sánchez,, ${ }^{1,2,3}$ J. L. Gómez Ribelles, ${ }^{1,2,3}$ M. Monleón Pradas, ${ }^{1,2,3}$ \\ J. M. Soria, ${ }^{4}$ M. E. Gomes, ${ }^{5,6}$ R. L. Reis, ${ }^{5,6}$ J. F. Mano 5,6 \\ ${ }^{1}$ Networking Research Center on Bioengineering, Biomaterials and Nanomedicine (CIBER-BBN), Valencia, Spain \\ ${ }^{2}$ Center for Biomaterials and Tissue Engineering, Universidad Politécnica de Valencia, Valencia 46022, Spain \\ ${ }^{3}$ Centro de Investigación Príncipe Felipe, Valencia 46013, Spain \\ ${ }^{4}$ Facultad de Ciencias de la Salud, Universidad CEU-Cardenal Herrera, Moncada, Valencia, Spain \\ ${ }^{5}$ Department of Polymer Engineering, 3B's Research Group-Biomaterials, Biodegradables and Biomimetics, \\ University of Minho, Braga 4710-057, Portugal \\ ${ }^{6}$ IBB - Institute for Biotechnology and Bioengineering, PT Government Associated Laboratory, Braga, Portugal
}

Received 29 July 2008; revised 19 January 2009; accepted 11 February 2009

Published online 13 May 2009 in Wiley InterScience (www.interscience.wiley.com). DOI: 10.1002/jbm.b.31400

\begin{abstract}
We have synthesized methacrylate-endcapped caprolactone networks with tailored water sorption ability, poly(CLMA-co-HEA), in the form of three-dimensional (3D) scaffolds with the same architecture but exhibiting different hydrophilicity character $\left(x_{\mathrm{HEA}}=0,0.3,0.5\right)$, and we investigated the interaction of goat bone marrow stromal cells (GBMSCs) with such structures. For this purpose, GBMSCs were seeded and cultured for 3, 7, 14, 21, and 28 days onto the developed scaffolds. Cells have proliferated throughout the whole scaffold volume. Cell adhesion and morphology were analyzed by SEM, whereas cell viability and proliferation was assessed by MTS test and DNA quantification concluding that numbers of cells increased as a function of the culturing time (until day 14) and also with the hydrophobic content in the samples (from 50 to $100 \%$ of CLMA). No significant difference between samples with $100 \%$ and $70 \%$ of CLMA were detected in some cases. Osteoblastic differentiation was followed by assessing the alkaline phosphatase activity of cells, as well as type I collagen and osteocalcin expressions levels until day 21 . The three markers were positive at days 14 and 21 when cells were cultured in $100 \%$ CLMA substrates which suggests osteoblastic differentiation of mesenchymal stem cells within these scaffolds. On the other hand, when the CLMA content decreases (until 50\%), type I collagen and osteocalcin were positive but ALP was negative indicating that the differentiation process is affected by hydrophilic content. We suggest that such system may be useful to extract information on the effect of materials' wettability on the corresponding biological performance in a 3D environment. Such general insights may be relevant in the context of biomaterials selection for tissue engineering strategies. (C) 2009 Wiley Periodicals, Inc. J Biomed Mater Res Part B: Appl Biomater 91B: 277-286, 2009
\end{abstract}

Keywords: MSCs; stem cells; osteogenic differentiation; caprolactone 2-(methacryloyloxy) ethyl ester; copolymers; scaffolds

\section{INTRODUCTION}

With the progressive ageing of world population, car accidents and other pathologies and trauma, the need for

Correspondence to: J. L. E. Ivirico (e-mail: joresciv@ter.upv.es)

Contract grant sponsor: Generalitat Valenciana; Contract grant number: BEFPI/ 2007/013

Contract grant sponsor: Spanish Ministry of Science; Contract grant number: MAT2007-66759-C03-01

(C) 2009 Wiley Periodicals, Inc. functional tissue substitutes is increasing. Today, organ, tissue transplantations and medical devices have an important role in medical practices but have limitations. Using autologous tissue in some affections has inconveniences such as complications of the harvesting procedure during operation, as well as the elaborate surgical procedure and the limited availability of autologous bone. Bone tissue engineering, combining bone marrow stromal cells (BMSCs) with a scaffolds and osteoinductive growth factors, provides a potential alternative to autologous bone grafts. 
Total porosity, pore size and shape, as well as pore interconnectivity determine the transport of nutrients and metabolites throughout the scaffold, which in the end modulate cell colonization and the ability of cells to deliver the adequate extracellular matrix. For artificial scaffolds to become osteoconductive, these are the clue factors in the conceptual design. ${ }^{1-4}$

In our previous work, ${ }^{5}$ it was shown that caprolactone 2-(methacryloyloxy) ethyl ester (CLMA) and 2-hydroxyethyl acrylate (HEA) can form homogeneous random copolymer networks when polymerized by free radical mechanism in solution of $N, N$-dimethylformamide (DMF). It was also shown that these materials could be used to produce three-dimensional (3D) scaffolds with varying water sorption ability since pure CLMA is hydrophobous and the addition of some HEA, monomeric units, rapidly increases water sorption. The effect of cell attachment and proliferation on the poly(CLMA) and poly(CLMA-coHEA) networks was observed by in vitro monolayer culture of human chondrocytes up to 8 days. It was shown that cell adhesion and proliferation onto the copolymer substrate containing $30 \%$ by weight of HEA units was approximately the same than onto poly(CLMA), both comparable to TCPS control.

By varying the HEA content in the system one can control, up to a certain extent, the wettability of the copolymer. It has been shown that the hydrophilic nature of the surface may strongly influence protein adsorption and cell adhesion. ${ }^{6}$ Such kind of studies has been mainly performed in $2 \mathrm{D}$ culturing conditions. We hypothesize in this work that the poly(CLMA-co-HEA) may provide a good model system to study the effect of wettability on the materialstem cell response in a 3D environment.

Research focused in tissue engineering strategies requires the use of adequate cell sources that should be viable in terms of clinical practice. Many works has been done involving the use of mesenchymal stem cells, since they are able to differentiate into various mesenchymal lineages. $^{7}$ In this context, goat BMSCs have been demonstrated to be an adequate model in validating tissue engineering strategies due to their high proliferation rate. Such cells differentiate into osteogenic or chondrogenic phenotypic cells in the presence of adequate culture media. ${ }^{8}$ The aim of this work is to extend that study to investigate the influence of substrate hydrophilic character on cell viability, proliferation, and differentiation in bone marrow cells cultured in osteogenic medium into 3D scaffolds made with these copolymers.

\section{EXPERIMENTAL}

\section{Materials}

Caprolactone 2-(methacryloyloxy)ethyl ester (CLMA) (Aldrich) and 2-HEA (Aldrich, 96\% pure) were used without further purification. Benzoin (Aldrich, 98\% pure) and ethylene glycol dimethacrylate (EGDMA) (Aldrich, 99\% pure) were used as initiator and crosslinking agent, respectively. Acetone (Scharlau, synthesis grade) and ethanol (Aldrich, 99.5\% pure) were used as solvents.

\section{Preparation of the Scaffolds}

Constructs with Spherical Pores. Poly(methyl methacrylate) (PMMA) microspheres with diameter $90 \pm 10 \mu \mathrm{m}$ (Colacryl dp 300) were used as porogen introducing them between two plates (of a self-built device) whose distance can be controlled by adjusting the step of a coupled screw and heated at $180^{\circ} \mathrm{C}$ for 30 min to obtain the first template. This template shows the highest porosity attainable (that will yield the lowest porosity of the scaffold) with typical compaction values of $60-65 \%$ for random monosized spherical particles. To obtain scaffolds with controlled porosity, the thickness of the obtained disk was first measured; then the disk was replaced in the mould and compressed at $180^{\circ} \mathrm{C}$ for half an hour. The degree of compression was quantified by measuring the thickness diminution.

After cooling the template at room temperature, a monomer solution (in different weight proportions of both components 100/0, 70/30, 50/50, CLMA/HEA, with 1 wt $\%$ of benzoin and 2 wt $\%$ of EGDMA) was introduced in the empty space between the PMMA spheres. ${ }^{5}$ The polymerization was carried out up to limiting conversion under a UV radiation source at room temperature.

After polymerization took place, the porogen template was removed by Soxhlet extraction with acetone for $48 \mathrm{~h}$. The porous sample was kept $24 \mathrm{~h}$ more in a Soxhlet with ethanol to extract low molecular weight substances. Samples were dried in vacuum to constant weight before characterization.

\section{Micro-Computed Tomography}

The qualitative information of the poly(CLMA) and poly(CLMA-co-HEA) scaffolds architecture was obtained by micro tomography imaging using a Scanco 20 equipment (Scanco Medicals, Switzerland) with penetrative X-rays of $50 \mathrm{keV}$. The X-ray scans were acquired in high-resolution mode. Mimics software (Materialise, Belgium) was used to visualize the $2 \mathrm{D} \mathrm{X}$-ray sections images of the materials layered scaffolds. From the $\mu$-CT data set, $150-160$ slices of a region of interest were used to investigate the interconnectivity of the pores.

\section{Isolation and Culture of GBMCs}

BMSCs were isolated from the iliac crest of adult goats and cultured with Dulbecco's Modified Eagle's Medium (DMEM; Sigma-Aldrich) supplemented with $10 \%$ fetal bovine serum (FBS; Gibco, UK) and antibioticantimycotic (1\% A/B, Gibco, UK) solution containing 10,000 units per $\mathrm{mL}$ penicillin $\mathrm{G}$ sodium, $10,000 \mathrm{mg} / \mathrm{mL}$ streptomycin 
sulfate, and $25 \mathrm{mg} / \mathrm{mL}$ amphotericin $\mathrm{B}$ as Fungizones ${ }^{\circledR}$ in $0.85 \%$ saline, as described in previous works. ${ }^{9}$

\section{Seeding and Culturing of GBMCs onto Poly(CLMA-co-HEA) 3D Scaffolds}

GBMCs cells were enzymatically lifted with $3 \mathrm{~mL}$ of trypsin (Sigma) after reaching $80 \%$ of confluence at P2. A cell suspension $\left(1 \times 10^{5}\right.$ cells in $50 \mu \mathrm{L}$ of medium $)$ was prepared and injected into the poly(CLMA-co-HEA) scaffolds (sterilized with $25 \mathrm{kGy}$ gamma radiation). The seeded scaffolds were then incubated at $37^{\circ} \mathrm{C}$ under $5 \%$ of $\mathrm{CO}_{2}$ conditions for $1 \mathrm{~h}$ and, after this time, an additional amount of fresh medium $(700 \mu \mathrm{L})$ was added to each well. For inducing osteogenic differentiation, cells/scaffolds constructs were cultured in 48-well plates for $3,7,14,21$, and 28 days with osteogenic differentiation media consisting of alpha-MEM (Minimal Essential Medium Eagle alpha modification, Sigma-Aldrich) supplemented with $10^{-8} \mathrm{M}$ dexamethasone (Sigma-Aldrich), $50 \mathrm{mg} / \mathrm{mL}$ ascorbic acid (Sigma), and $10 \mathrm{~m} M \beta$-glycerophosphate (Sigma). Osteogenic medium was renewed every $2-3$ days. Each experiment was performed in triplicate.

\section{Characterization of Cell-Scaffold Constructs}

Cell Viability. Cell viability was assessed by the MTS cell proliferation assay which quantified mithocondrial activity by measuring the formation of a soluble formazan product, which directly proportional to the number of living cells. After $3,7,14,21$, and 28 days of cultured, cells-CLMA/HEA scaffold constructs were transferred into a 48-well plate and washed twice with sterile PBS. Culture medium without FBS and without phenol red was mixed with MTS in a 5:1 ratio, added to the wells, until total cover of the constructs, and incubated for $3 \mathrm{~h}$ at $37^{\circ} \mathrm{C}$ in a $5 \% \mathrm{CO}_{2}$. After the incubation period, $100 \mu \mathrm{L}$ of MTS and medium mixture were transferred into each well of a 96-well plate and absorbance was read in a microplate reader (Bio-Tek) at $490 \mathrm{~nm}$.

Evaluation of GBMCs Adhesion and Morphology. GBMCs adhesion and morphology were investigated by Scanning Electron Microscopy, SEM (Leica Cambridge S360, UK). For this purpose, after each culturing period, samples were removed from the culture well, washed in PBS, fixed in $2.5 \%$ glutaraldehyde, rinsed twice with PBS, and dehydrated in a series of ethanol concentrations $(30 \%$, $50 \%, 70 \%, 90 \%$, and absolute) for 15 min with final dehydration in absolute ethanol for $30 \mathrm{~min}$. Finally, samples were dried at room temperature and sputter coated with gold [using a Fisons Instrument Coater (Polaron SC 502, UK)] before observation with SEM.

Assessment of GBMCs Proliferation by Fluorimetric Analysis. GBMCs proliferation in the prepared scaffolds was determined using a fluorimetric dsDNA quantification kit (PicoGreen, Molecular Probes). Samples collected on days $3,7,14,21$, and 28 were transferred into $1.5 \mathrm{~mL}$ microtubes containing $1 \mathrm{~mL}$ of ultra-pure water and stored at $-80^{\circ} \mathrm{C}$ until testing. Before DNA quantification, constructs were thawed and sonicated for $15 \mathrm{~min}$. Samples and standards (ranging between 0 and $2 \mu \mathrm{g} / \mathrm{mL}$ ) were prepared by adding per each well of an opaque 96-well plate $28.7 \mu \mathrm{L}$ of either sample or standard, $71.3 \mu \mathrm{L}$ of PicoGreen solution, and $100 \mu \mathrm{L}$ of Tris-EDTA buffer. The plate was incubated for $10 \mathrm{~min}$ in the dark and fluorescence was measured on a microplate ELISA reader (BioTek) at $520 \mathrm{~nm}$ using an emission source of $490 \mathrm{~nm}$. A standard curve was created and sample DNA values were read off from the standard graph. Each experiment was performed in triplicate.

Assessment of GBMCs Proliferation by Inmunofluorescence. Cell-poly(CLMA) constructs were washed in PBS, $0.1 M$ for $5 \mathrm{~min}$, fixed with formalin solution for $1 \mathrm{~h}$ and washed with PBS twice. After rinsed with $\mathrm{H}_{2} \mathrm{O}_{2}$ for 5 min for three times, unspecific immune reactions were blocked using a blockade solution (BS) [8.9 mL of PBS $(0.1 M), 1 \mathrm{~mL}$ of FBS $(10 \%)$, and $0.1 \mathrm{~mL}$ of Triton $(0.1 \%)]$ for $2 \mathrm{~h}$ at room temperature. After that, Antihuman Mouse Alkaline Phofatase antibody (R\&D System) (for ALP detection), or Antihuman rabbit collagen I antibody (Chemicon) (for type I collagen), or Antihuman Mouse Osteocalcin antibody (R\&D System) were administrated for $1 \mathrm{~h}$ at room temperature and overnight at $4{ }^{\circ} \mathrm{C}$. Cell-scaffold constructs were washed three times with PBS $(0.1 M)$ and were incubated with secondary antibody (1:200 in BS) for $2 \mathrm{~h}$ at room temperature. Then, samples were rinsed three times with PBS for $5 \mathrm{~min}$ and DAPI (1/5000 in PBS, 0.1M) was added. The evaluation was done by [Leica TCS SP2 AOBS (Leica Microsystems Heidelberg GmbH, Mannheim, Germany)] Confocal Microscopy. Two-dimensional (2D) pseudocolor images (255 color levels) were gathered with a size of $1024 \times 1024$ pixels.

To visualize type I collagen, the cells-scaffold constructs were monitored in the confocal microscope, using a $20 \mathrm{X}$ Plan-Apochromat Lambda Blue 0.70 IMM objective, with a single excitation $(405 \mathrm{~nm})$ and a single emission system (411-451 nm), with one multiplier for blue fluorescence. Double-labeled preparation was monitored in the confocal microscope, using a 40X Plan-Apochromat 1.25 N.A. oil objective, with a double excitation (405 nm, $488 \mathrm{~nm}$ ) and a double emission system (411-451 nm, 501-594 nm), with two multipliers for blue and green fluorescence to determine osteocalcin. Alkaline phosphatase (ALP) was detected using double-labeled preparation in the confocal microscope, with a double excitation (405 nm, $561 \mathrm{~nm}$ ) and a double emission system (411-451 nm, 571-664 nm), with two multipliers for blue and red fluorescence.

\section{Statistical Analysis}

Student's $t$-test of two samples assuming equal variance, and ANOVA, single factor tests were used to compare 


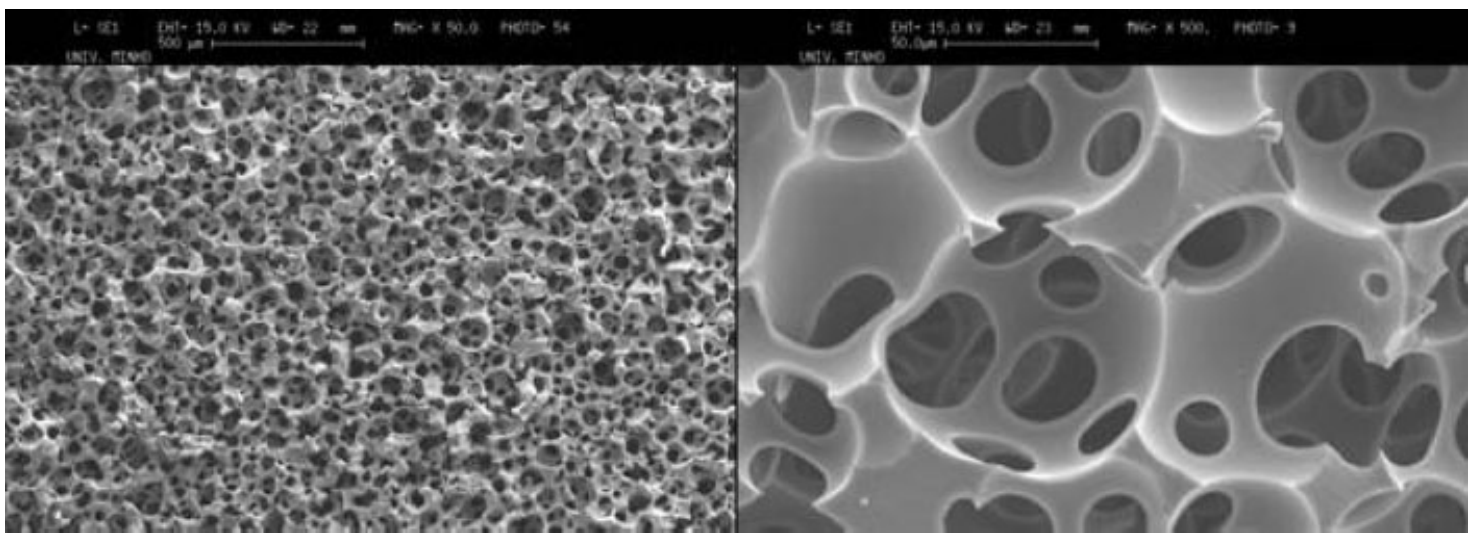

Figure 1. SEM micrographs of poly(CLMA) network scaffold at different magnifications.

between samples, data considered significant for $* p$ values $<0.05$. The statistical analysis comes from proliferation and MTS experimental data.

\section{RESULTS}

\section{Pore Architecture of the Scaffolds}

The scaffolds prepared in this work are similar to those reported in reference. ${ }^{5}$ SEM micrographs of the resulting scaffolds (Figure 1) show the pore architecture consisting of a network of interconnected spherical pores. Figure 1 corresponds to poly(CLMA) network but the same geometrical structure was obtained with poly(CLMA-co-HEA) copolymers with different amounts of HEA (30 and 50\% of HEA).

A deeper insight into the pore architecture was obtained using micro-computed tomography, $\mu$-CT, that allowed a quantitative characterization of pore size and interconnectivity. Figure 2 shows a representative 2D section of a CLMA scaffold. 3D reconstruction of the scaffolds geometry allows one to calculate the total porosity and the pore size distribution, ${ }^{10}$ which is shown in Figure 3 . The mean pore diameter is $\sim 90 \mu \mathrm{m}$, according to the diameter of the porogen particles used in the preparation of the scaffold (Figure 3).

\section{Adhesion and Proliferation of GBMCs Cultured onto Poly(CLMA) and Poly(CLMA-co-HEA) Scaffolds}

Cell seeding into the scaffolds was performed by injecting in the center of the scaffold a suspension of GMBCs using a micro syringe. In this way, cell suspension is initially forced to fill in the whole volume of the pores. Despite the volume of medium in which cells were suspended was as small as possible $(50 \mu \mathrm{L})$, it is larger than the pore volume of the sample and a part of the suspension and thus a fraction of cells leaves the sample (and is retained in the well). One hour after seeding, the samples were transferred to new well-plates with fresh culture medium to stimulate the adhesion of the cells to the scaffold.
Figure 4 shows the SEM micrographs of the surface of poly(CLMA) samples seeded with GBMCs and cultured in osteogenic medium at different culture times $(3,7,14,21$, and 28 days). Also, a detail at higher magnification (Figure 5) shows the cells on the scaffold transversal section of poly(CLMA) at day 21, which shows that cells adhere to the substrate, spread actively, and present a flat morphology.

The influence of the chemical composition of the scaffold on GBMCs culture can be observed on the surface of the scaffolds after 21 days of culture (refer the SEM pictures in Figure 6). The fraction of surface covered by cells and extracellular matrix is much lower in poly(CLMA-coHEA) 50/50 copolymer than in poly(CLMA).

The amount of DNA per sample (Figure 7) showed an important increase of the number of cells from day 3 to day 28 in all the scaffolds and hence a high cellular proliferation occurred in presence of osteogenic medium. No significant differences were found between the behavior of poly(CLMA) scaffolds and those containing 30\% HEA

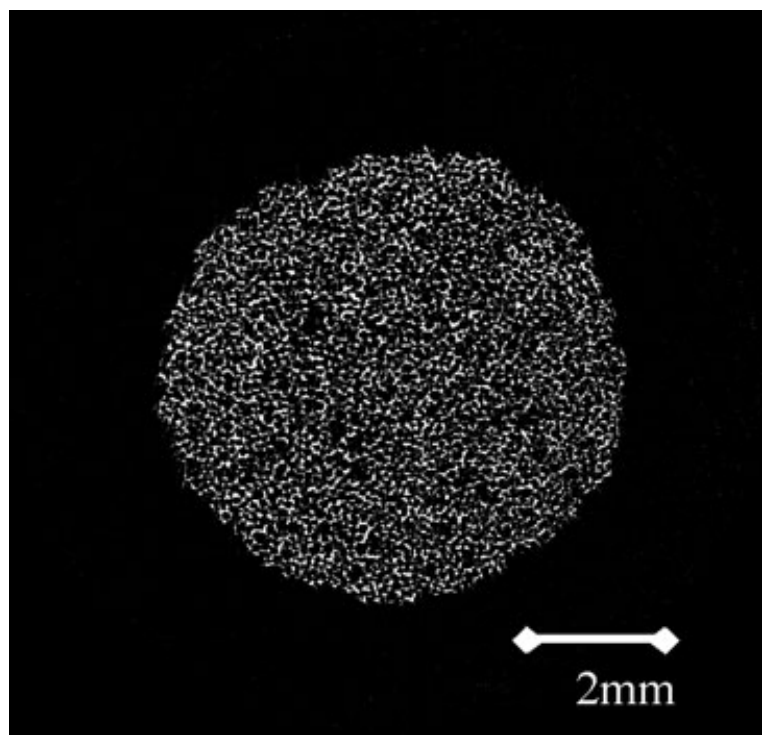

Figure 2. $\mu$-CT transversal images of poly(CLMA). 


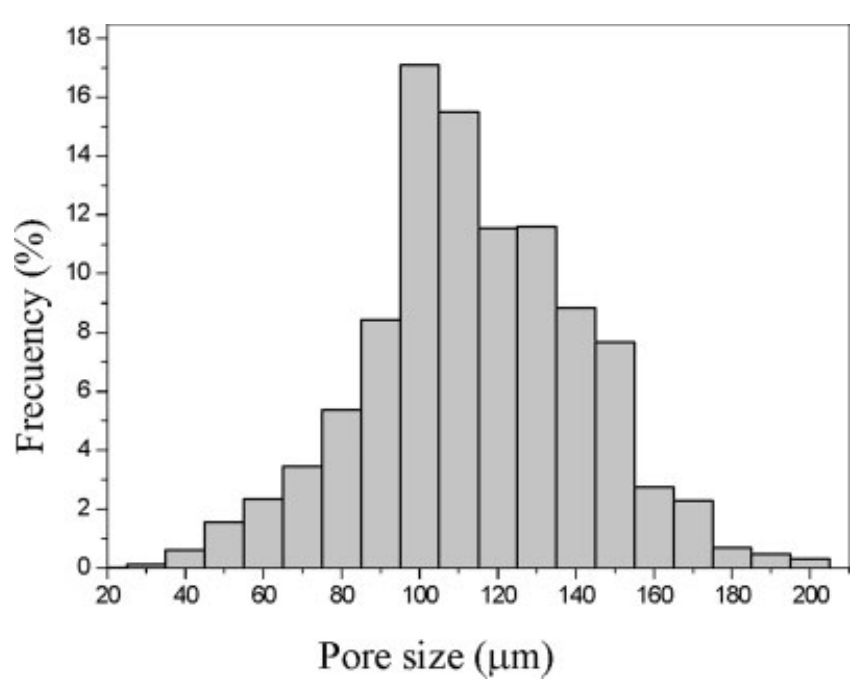

Figure 3. Pore size distributions for the CLMA structures.

with the exception of the MTS experiment at day 3. Nevertheless, the number of cells is much smaller in the copolymer containing 50\% HEA than in poly(CLMA) confirming the influence of hydrophilic character on cell proliferation. For example, even for the longest culture times, the DNA content is slightly higher in the scaffold containing $30 \%$ HEA. These results are confirmed by the MTS assay (Figure 8) and show cell viability and proliferation when culturing GMBC in osteogenic medium seeded in the pol$y$ (CLMA) scaffolds or containing small amounts of the hydrophilic component to improve water diffusion through the construct.

\section{Osteogenic Differentiation}

Scaffolds cultured for different time periods were cross sectioned in thick slices and observed with confocal microscope after inmunofluorescence assays. Figure 9(a-f) show different sections of a poly(CLMA) scaffold at days $14(\mathrm{a}, \mathrm{b}, \mathrm{c})$ and $21(\mathrm{~d}, \mathrm{e}, \mathrm{f})$. In all of them, the nuclei of the cells were counterstained with DAPI (blue). These images confirm that a high number of cells has invaded the interior of the scaffold and the number of positive cells for ALP, type I collagen, and osteocalcin markers increase with the amount of CLMA in the scaffolds. The behavior of the cells cultured in poly(CLMA-co-HEA) (50/50) was different. A few cells can be found in cross sections of these copolymer scaffolds as shown in Figure $9(\mathrm{~g}-\mathrm{i})$, confirming the results of MTS assay and DNA content described above. Osteocalcin and type I collagen markers are positive, but in the case of ALP the result was negative.

\section{DISCUSSION}

The procedure used to process the porous constructs permitted to obtain a series of macroporous scaffolds with tailored chemical structure of the pore surface that interact with cells but keeping the same pore architecture and porosity ( $\sim 72 \%$ as calculated from microCT) for all of them. In particular, surface tension is greatly affected by the presence of hydroxyl groups and also equilibrium water content of the bulk material in immersion in liquid water or culture medium [maximum water absorption, $w$, for poly(CLMA) was 0.1 and for poly(CLMA-co-HEA) (30/70) was 1]. ${ }^{5}$

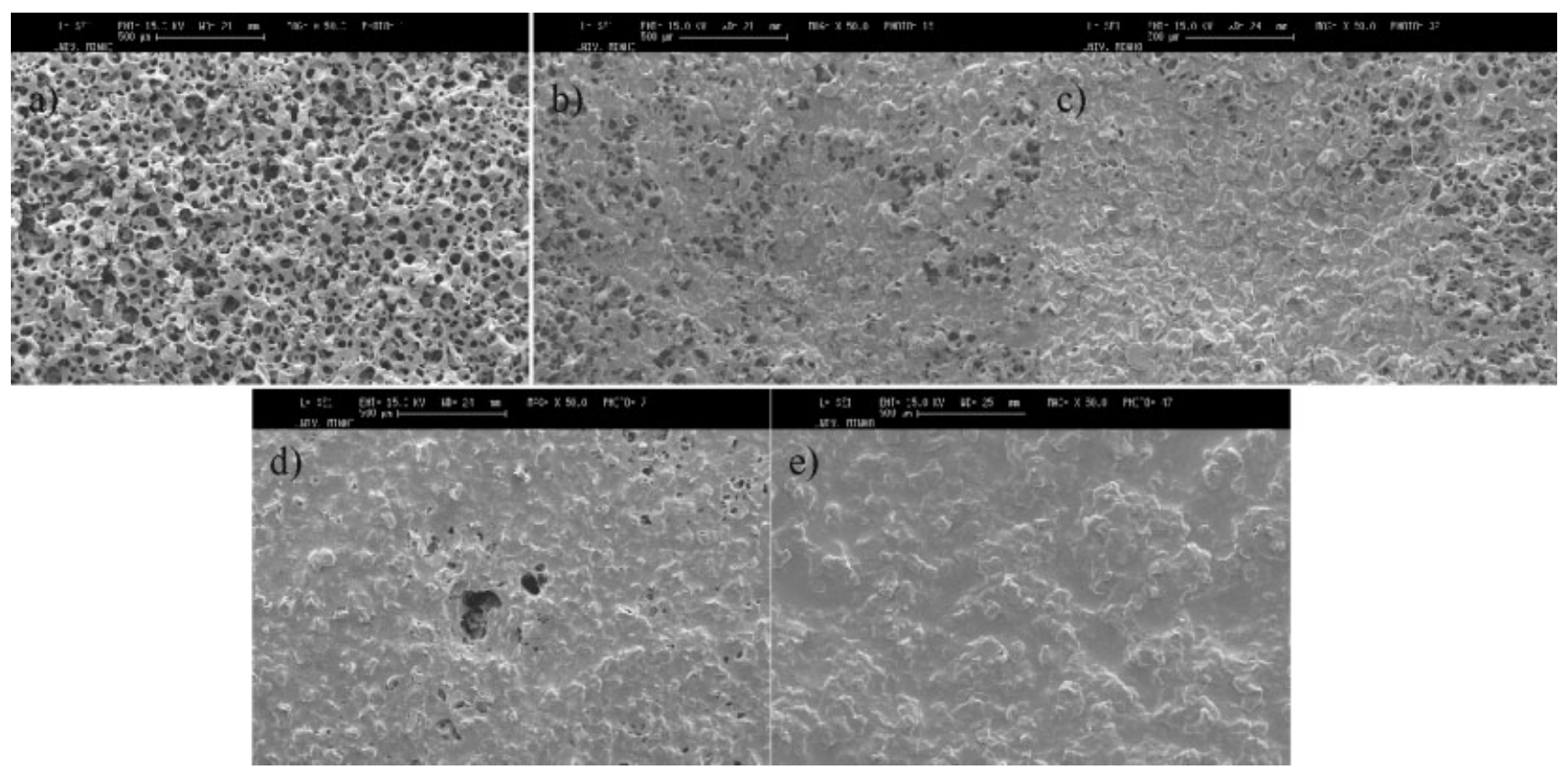

Figure 4. SEM micrographs of poly(CLMA) scaffolds seeded with GBMCs and culture for 28 days in osteogenic media: day 3 (a), day 7 (b), day 14 (c), day 21 (d), and day 28 (e). 


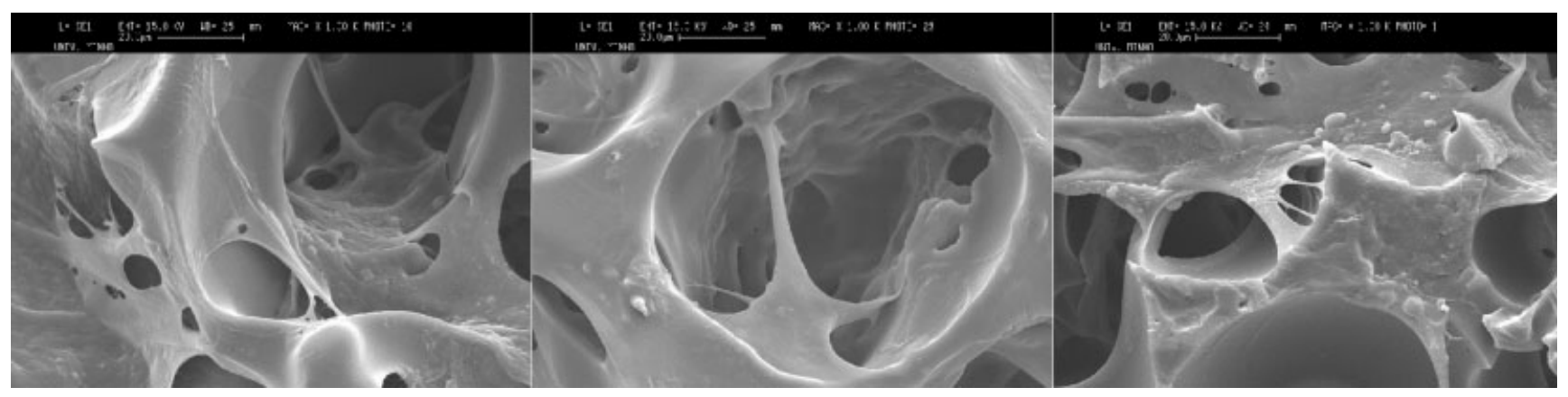

Figure 5. SEM micrographs of poly(CLMA) scaffolds seeded with GBMCs in day 21 with osteogenic media: scaffold transversal section.

The increase in water absorption ability and surface tension with increasing HEA content is expected to improve the scaffold wettability, enhancing cell seeding, and transport of nutrients and other water soluble products to the whole volume of the scaffold. Nevertheless, the increase of hidrophilicity could lead to decrease cell adhesion to the substrate. The balance between these factors must determine the viability of cells cultured in 3D scaffolds.

Pore size distribution within the scaffolds is mostly unaffected by the chemical composition of the underlying material, i.e., the architecture of the scaffold is mainly determined during the sintering process of the PMMA template and it does not change due to the polymerization of different chemical components. The pore size is determined by the size of the porogen particles but also by the polymer contraction when drying after porogen elimination with a suitable solvent. ${ }^{11}$ Thus, pore architecture could in principle vary with the copolymer composition. Nevertheless, this was not the case in the series of samples of this work and pore structure shown in Figure 1, and the pore size distribution of Figure 3 are representative of all compositions. A more detailed analysis of the scaffolds architecture has been reported elsewhere. ${ }^{10}$

Cellular density increases with time (Figure 4), suggesting adequate adhesion and proliferation. After 21 days, the complete surface of the scaffold is covered by cells and extracellular matrix. On the other hand, the presence of high cell density inside the scaffold can be proved observing thick cross sections of the samples using confocal microscopy after fluorescent staining of the cell nuclei with DAPI (Figure 9). Cross sections of the scaffold were also observed by SEM (Figure 5) demonstrating the cell colonization of the interior of the scaffolds besides their growth and adhesion to the surface of the material. Results were similar for other copolymer composition.

The fraction of surface covered by cells and extracellular matrix markedly decreases in poly(CLMA-co-HEA) 50/ 50 copolymer with respect to poly(CLMA). Nevertheless, the behavior of the copolymer containing 30\% HEA is similar to that of poly(CLMA) homopolymer. This fact is confirmed by the MTS assay (Figure 8) where, with the exception of day 3 , there are not statistical significant differences between both samples. Also in the same figure we can see how the viability is similar at 14 and 21 days of culture, but the cells number is double after 21 days with respect to day 14 (refer Figure 7). Even if these results might be related to higher cell death rates after day 14 , it cannot be excluded that MTS assay underestimates the number of viable cells for high the cell densities due to the difficulty for the reactive to access all the cells inside the 3D scaffolds.

From Figure 8 we can conclude that the 3D scaffolds made of poly(CLMA) and poly(CLMA-co-HEA) copolymers with up to $30 \mathrm{Wt} \%$ HEA support viability of GBMCs.
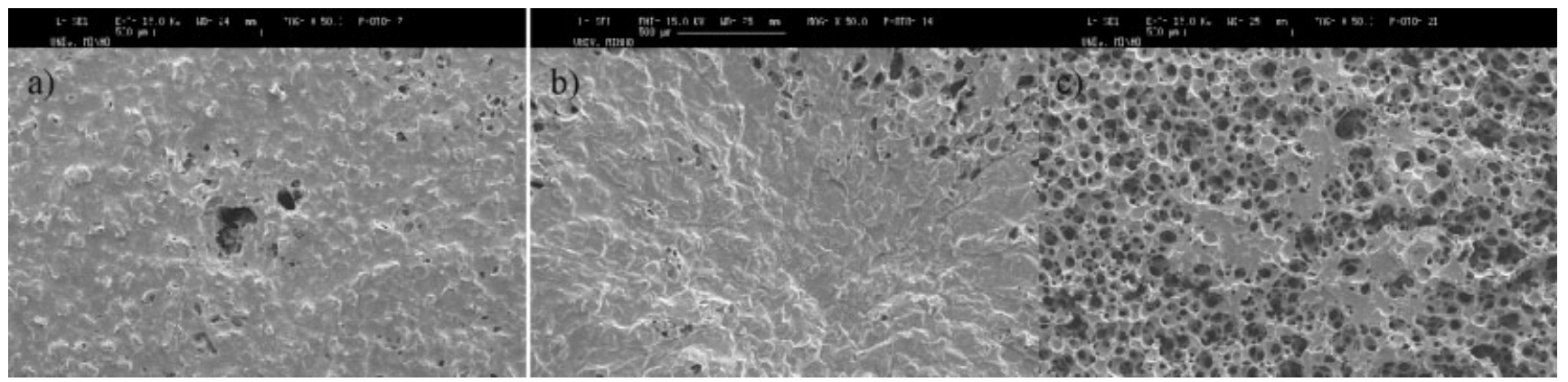

Figure 6. SEM micrographic of poly(CLMA-co-HEA) at day 21. Figure 6(a-c) correspond to poly(CLMA-co-HEA) with (100/0), (70/ $30)$, and (50/50), respectively. 


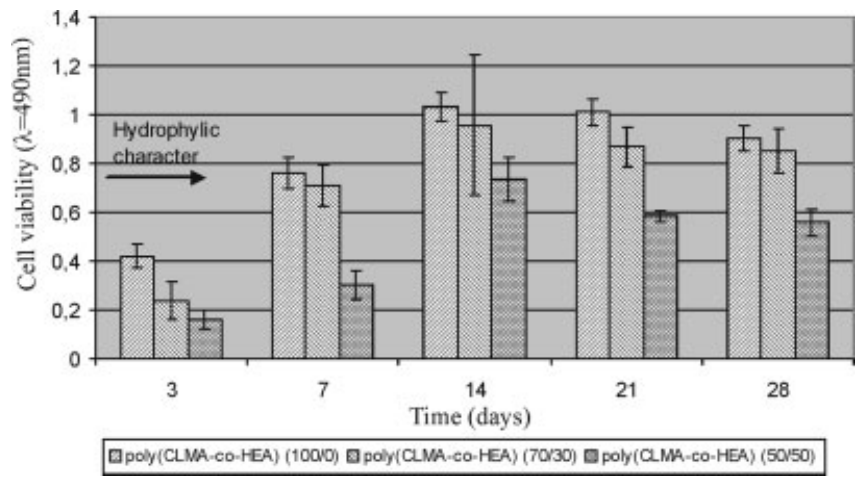

Figure 7. DNA content of GBMCs on poly(CLMA-co-HEA) with different compositions after $3,7,14,21$, and 28 days in osteogenic media.

The porosity and interconnectivity of the pore structure ensures the supply of nutrients to cells in the culture in static conditions. Further increase in HEA content and thus of the hydrophilicity rapidly reduces cell numbers inside the scaffold. This feature can be due to the decreased adhesion of the cells to the substrate. When the distribution of the hydrophilic groups on substrate's surface is homogeneous it has been found that some types of cell attach more to hydrophobic substrates, and cell adhesion decreases monotonously with the fraction of hydrophilic groups on the surface. This was the case of chondrocytes cultured in monolayer on poly(EA-co-HEA) or poly(EMA-co-HEMA) substrates, ${ }^{12-17}$ or normal human conjunctival epithelial cells $^{18}$ or human umbilical cord vein cells ${ }^{19}$ in both cases cultured on poly(EA-co-HEA), similar results were obtained. ${ }^{19-23}$ Nevertheless, the optimal composition of this type of scaffolds based on copolymers with a hydrophobic and a hydrophilic components does not always correspond to the hydrophobous material, intermediate compositions containing between $0 \%$ and $50 \%$ of the hydrophilic component were more adherent for central nervous system cells. ${ }^{24}$ This situation was also observed when the hydrophilic groups cluster forming nanodomains on the surface as hap- pened in human chondrocytes cultured on poly(EA-coHEMA) substrates. ${ }^{17}$

The differences in cell adhesion have been attributed to differences in protein adsorption and conformation on these surfaces. For example, cultured MC3T3-E1 osteoblasts ${ }^{25}$ on surfaces with uniform distribution of different chemical groups coated with fibronectin and were able to correlate cell attachment and localization of focal adhesions with the exposition of the central module of fibronectin molecule, where the RGD ligands for integrins reside. The influence of substrate hydrophilicity and the distribution of hydrophilic groups on the conformation of proteins adsorbed has been also reported elsewhere ${ }^{26,27}$ and correlated with cell attachment.

Proliferation of the cells lodged into the pores of the scaffold requires cell attachment to the pore walls as shown in SEM picture of Figure 5. Additionally, a homogeneous cell distribution and growth towards the interior of the scaffold is difficult to achieve under static culturing. ${ }^{28}$

Osteogenic cells require an interaction with the extracellular matrix for their growth, maturation, and survival.

Differentiation of GBMCs into bone-forming cells can be assessed characterizing the expression of some makers and the composition of extracellular matrix that correlate with osteoblastic phenotype such as ALP levels, type I collagen, some non-collagenous proteins such as osteocalcin and finally the formation-in a controlled cell-mediated way-of a calcified extracellular matrix. Figure 9(a,d) show (in red) the presence of type I collagen, which is the predominant protein of bone matrix and its expression and secretion is critical for mineralization process. Attachment to type I collagen is mediated through integrins that activate kinase signaling pathways, thus supporting osteoblast cell proliferation and bone growth. ALP is a cell-surface glycoprotein that is involved in mineralization and detected during the early differentiation process. Figure $9(\mathrm{c}, \mathrm{f})$ reveal the presence of the ALP marker (red color) inside the scaffolds at 14 and 21 days culture. Figure 9(b,e) show the presence of osteocalcin in the extracellular matrix but not in all the regions occupied by the cells. Osteocalcin is a

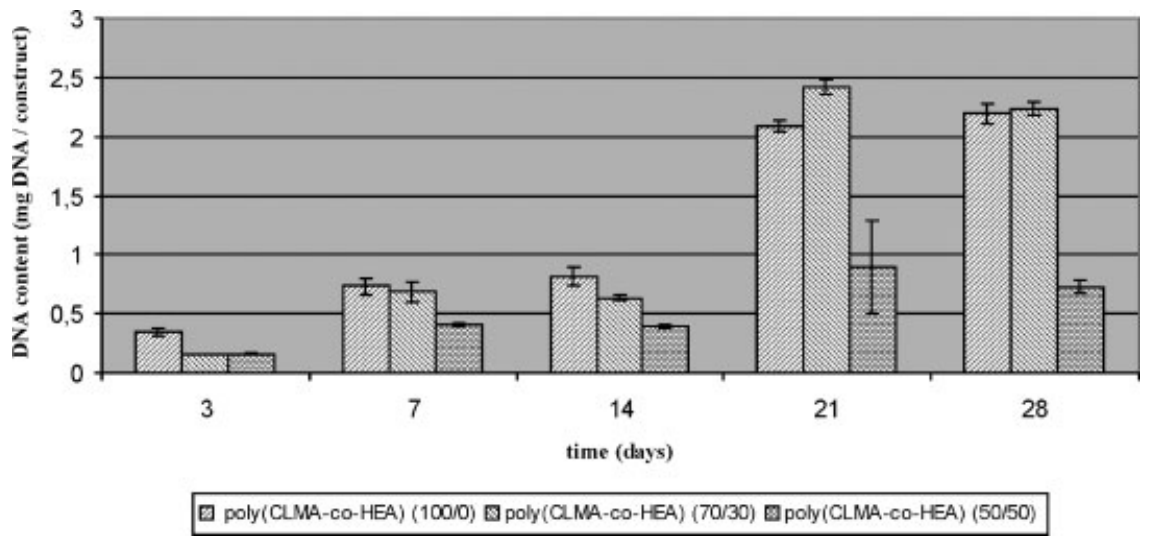

Figure 8. Viability levels of GBMCs on poly(CLMA-co-HEA) with different compositions after 3, 7, 14, 21, and 28 days in osteogenic media. 


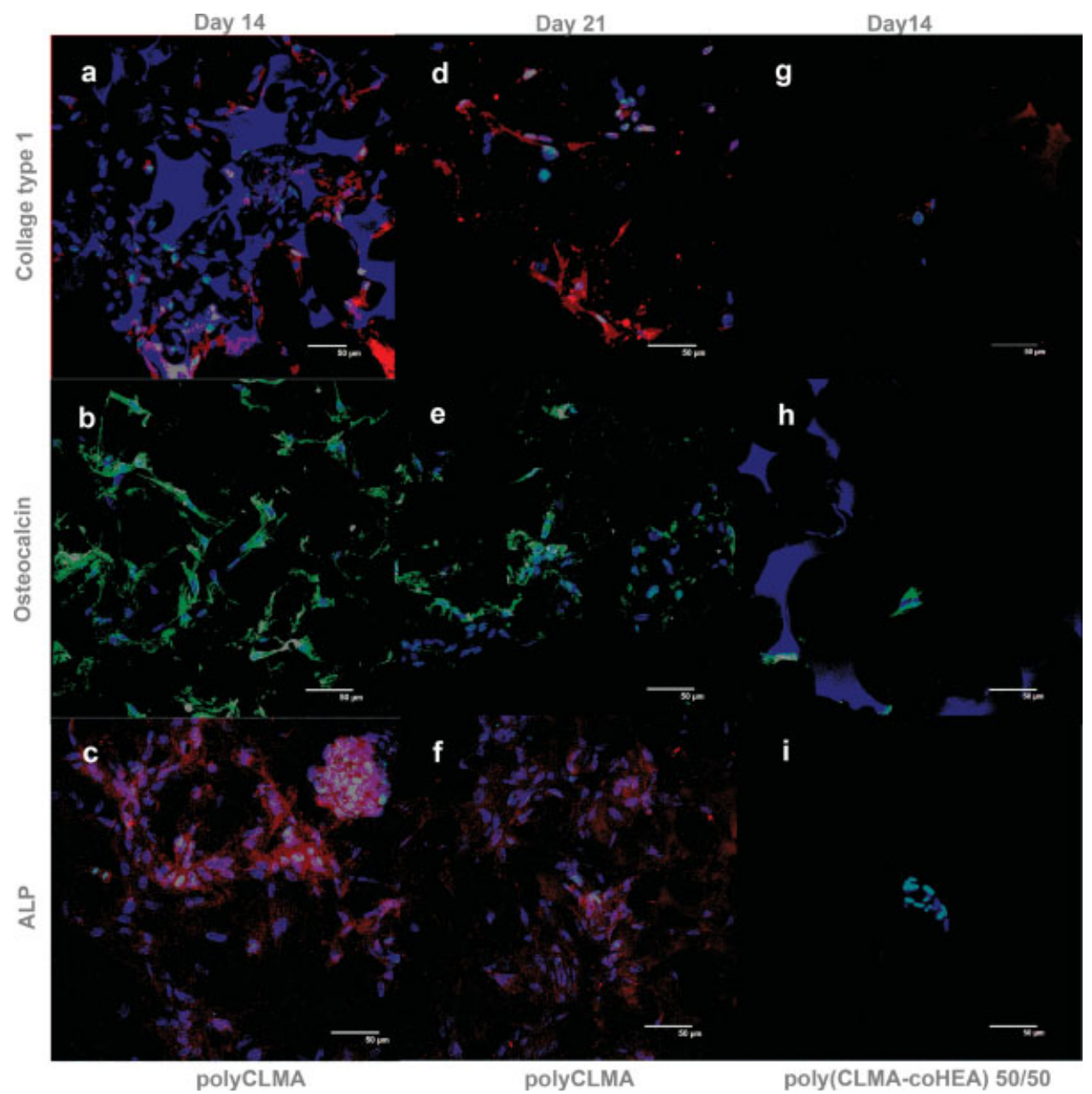

Figure 9. Immunohistochemistry analysis of osteoblast related protein expression in GBMCs culture on poly(CLMA) scaffolds. Cultured cells expressed the extracellular matrix proteins: Type I collagen (Figures a and d for day 14 and 21, respectively) and osteocalcin (b and e for day 14 and 21, respectively). ALP activity was also detected (c and $f$ at days 14 and 21, respectively). Figure $9(\mathrm{~g}-\mathrm{i})$ correspond to the type I collagen, osteocalcin, and ALP immunohistochemistry of GBMCs in poly(CLMA-co-HEA) (50/50).

matrix protein that regulates osteoclast activity and which characterizes the post proliferative phase. ${ }^{29}$ Thus Figure $9(\mathrm{~b}, \mathrm{e})$ suggest that osteogenic differentiation is not complete after 21 days of culture in osteogenic medium. These results confirm that GBMCs cultured in this kind of scaffolds for such time periods have characteristics of osteoprogenitor cells and exhibit other features of pre-osteoblasts. In fact, it has been demonstrated in several studies that the BMSCs are able to proliferate and differentiate to osteoblast (using biochemical stimulation provided by the osteogenic components of the culture medium), but mineralization can only occur in short culture periods when cells are also submitted to other stimulus, such as mechanical stimulation provided dynamic culture conditions (in perfusion bioreactors). ${ }^{28}$

Figure $9(\mathrm{~g}-\mathrm{i})$ show the inmunofluorescence pictures of cross sections of poly(CLMA-co-HEA) 50/50 scaffolds. In good agreement with the MTS and DNA, the number of cells inside the scaffold is clearly much smaller than in
poly(CLMA) but the cells expressed type I collagen and osteocalcin, although ALP test was negative.

Concluding, the samples with $100 \%$ of CLMA and $70 \%$ of CLMA present a similar pore size distribution, interconnectivity, and the same behavior in the GBMCs cell cultures. This is the reason why, if a material should be chosen to further applied research, the scaffold with $70 \%$ of CLMA would be selected since, in addition to the above-described features, this system presents adequate hydrophilicity that allows enhancing of nutrients transport to the whole volume of the scaffold.

\section{CONCLUSIONS}

3D scaffolds made of copolymers that combine hydroxyethyl acrylate and caprolactone units have proven to sustain GBMCs adhesion and proliferation. The method of injecting a cell suspension inside the scaffolds has proved to be 
effective in seeding a cell population uniformly distributed in the pore structure. Culture of the scaffolds in osteogenic medium maintains proliferation while the cells express characteristic osteogenic markers such as type I collagen, ALP, and osteocalcin. It can be concluded that the best behavior was found when cells were cultured in hydrophobic scaffolds containing small amount of the hydrophilic component (up to $30 \%$ ). This system allows one to improve diffusion of water and bioactive molecules through the scaffold without compromising the biological response. Nevertheless, HEA content above $50 \%$ reduces the cell viability and proliferation.

The support from the Generalitat Valenciana through shortterm fellowship is kindly acknowledged. JLGR acknowledge the support of the Spanish Ministry of Science (including the FEDER financial support).

\section{REFERENCES}

1. Gross AE. Cartilage resurfacing: Filling defects. J Arthroplasty 2003;18:14-17.

2. Chu CR, Coutts RD, Yoshioka M, Harwood FL, Monosov AZ, Amiel D. Articular cartilage repair using allogeneic perichondrocyte-seeded biodegradable porous polylactic acid (PLA): A tissue engineering study. J Biomed Mater Res 1995;29:1147-1154.

3. Caplan AI, Elyaderani M, Mochizuki Y, Wakitani S, Goldberg VM. Principles of cartilage repair and regeneration. Clin Orthop 1997;342:254-269.

4. Schaefer D, Martin I, Shastri P, Padera RF, Langer R, Freed LE, Vunjak-Novakovic G. In vitro regeneration of osteochondral composites. Biomaterials 2000;21:2599-2606.

5. Escobar Ivirico JL, Costa Martínez E, Salmerón Sánchez M, Muñoz Criado I, Gómez Ribelles JL, Monleón Pradas M. Methacrylate-endcapped caprolactone networks hydrophilized by copolymerization with 2-hydroxyethyl acrylate. J Biomed Mater Res Part B: Appl Biomater 2007;83B:266-275.

6. Arima Y, Iwata $\mathrm{H}$. Effect of wettability and surface functional groups on protein adsorption and cell adhesion using welldefined mixed self-assembled monolayers. Biomaterials 2007;28:3074-3082.

7. Jiang Y, Jahagirdar BN, Reinhardt RL, Schwartz RE, Keene $\mathrm{CD}$, Ortiz-Gonzalez XR, Reyes $\mathrm{M}$, Lenvik $\mathrm{T}$, Lund $\mathrm{T}$, Blackstad M, Du J, Aldrich S, Lisberg A, Low WC, Largaespada DA, Verfaillie CM. Pluripotency of mesenchymal stem cells derived from adult marrow. Nature 2002;418:41-49.

8. Oliveira JM, Rodrigues MT, Silva SS, Malafaya PB, Gomes ME, Viegas CA, Dias IR, Azevedo JT, Mano JF, Rui Reis RL. Novel hydroxyapatite/chitosan bilayered scaffold for osteochondral tissue-engineering applications: Scaffold design and its performance when seeded with goat bone marrow stromal cells. Biomaterials 2006;27:6123-6137.

9. Hunziker EB. Articular cartilage repair: Basic science and clinical progress. A review of the current status and prospects. Osteoarthritis Cartilage 2002;10:432-463.

10. Alberich-Bayarri A, Moratal D, Escobar Ivirico JL, Rodríguez Hernández JC, Vallés-Lluch A, Martí-Bonmatí L, Más Estellés J, Mano JF, Monleón Pradas M, Gómez Ribelles JL, Salmerón Sánchez M. Micro-computed tomography and micro-finite ele- ment modeling for evaluating polymer scaffolds architecture and their mechanical properties. J Biomed Mater Res Part B: Appl Biomater. DOI: 10.1002/jbm.b.31389.

11. Brígido Diego R, Más Estellés J, Sanz JA, García-Aznar JM, Salmerón Sánchez M. Polymer scaffolds with interconnected spherical pores and controlled architecture for tissue engineering. Fabrication, mechanical properties, and finite element modelling. Biomed Mater Res Part B: Appl Biomater 2007;81B:448-455.

12. Chirila TV, Constable IJ, Crawford GJ, Vijayasekaran S, Thompson DE, Chen YC, Fletcher WA, Griffin BJ. Poly(2hydroxyethyl methacrylate) sponges as implant materials: In vivo and in vitro evaluation of cellular invasion. Biomaterials 1993;14:26-38.

13. Chirila TV, Chen YC, Griffin BJ, Constable IJ. Hydrophilic sponges based on 2-hydroxyethyl methacrylate. Part I. Effect of monomer mixture composition on the pore size. Polym Int 1993;32:221-232.

14. Clayton AB, Chirila TV, Dalton PD. Hydrophilic sponges based on 2-hydroxyethyl methacrylate. Part III. Effect of incorporating a hydrophilic crosslinking agent on the equilibrium water content and pore structure Polym Int 1997;42: 45-56.

15. Vijayasekaran S, Fitton JH, Hicks CR, Chirila TV, Crawford GJ, Constable IJ. Cell viability and inflammatory response in hydrogel sponges implanted in the rabbit cornea. Biomaterials 1998; 19:2255-2267.

16. Ziegelaar BW, Fitton JH, Clayton AB, Platten ST, Maley MAL, Chirila TV. The modulation of corneal keratocyte and epithelial cell responses to poly(2-hydroxyethyl methacrylate) hydrogel surfaces: Phosphorylation decreases collagenase production in vitro. Biomaterials 1999;20:19791988.

17. Pérez Olmedilla M, Garcia-Giralt N, Monleón Pradas M, Benito Ruiz P, Gómez Ribelles JL, Cáeres Palou E, Monllau García JC. Response of human chondrocytes to a non-uniform distribution of hydrophilic domains on poly(ethyl acrylate-cohydroxyethyl methacrylate) copolymers. Biomaterials 2006;27:1003-1012.

18. Diebold Y, Calonge M, Enríquez de Salamanca A, Callejo S, Corrales RM, Saez V, Siemasko KF, Stern ME. Characterization of a spontaneously immortalized cell line (IOBA-NHC) from normal human conjunctiva. Invest Ophthalmol Vis Sci 2003;44:4263-4274.

19. Campillo-Fernández AJ, Abad Collado M, Bataille L, GómezRibelles JL, Meseguer-Dueñas JM, Monleón-Pradas M, Pastor $\mathrm{S}$, Artola A, Alió JL, Ruiz-Moreno JM. Future design of a new keratoprosthesis. Physical and biological analysis of polymeric substrates for epithelial cell growth. Biomacromolecules 2007;8:2429-2436.

20. Lyndon MJ. Synthetic hydrogels as substrata for cell adhesion studies. Br Polym J 1986;18:22-27.

21. Lyndon MJ, Minett TW, Tighe BJ. Cellular interactions with synthetic polymer surfaces in culture. Biomaterials 1985;6:396-402.

22. Rosen JJ, Schway MB. Kinetics of cell adhesion to a hydrophilic-hydrophobic copolymer model system. Polym Sci Technol 1980;12:667-675.

23. Soria JM, Martínez Ramos C, Bahamonde O, García Cruz DM, Salmerón Sánchez M, García Esparza MA, Casas C, Guzmán M, Navarro X, Gómez Ribelles JL, García Verdugo JM, Monleón Pradas M, Barcia JA. Influence of the substrate's hydrophilicity on the in vitro Schwann cells viability. J Biomed Mater Res Part A 2007;83A:463-470.

24. Kiremitçi M, Serbetei AI, Çolak R, Pịskin E. Cell attachment to PU and PHEMA based biomaterials: Relation to structural properties. Clin Mater 1991;8:9-16. 
25. Horbett TA, Schway MB, Ratner BD. Hydrophilic-hydrophobic copolymers as cell substrates: Effect on 3T3 cell growth rates. J Colloid Interface Sci 1985;104:28-39.

26. Keselowsky BG, Collard DM, García AJ. Surface chemistry modulates fibronectin conformation and directs integrin binding and specificity to control cell adhesion. J Biomed Mater Res 2003;66A:247-259.

27. Rodríguez Hernández JC, Salmerón Sánchez M, Soria JM, Gómez Ribelles JL, Monleón Pradas M. Surface chemistry- dependent conformations of single laminin molecules on polymer surfaces are revealed by the phase signal of atomic force microscopy. Biophys J 2007;93:202-207.

28. Costa PF, Martins AM, Neves NM, Gomes ME, Reis RL. A novel bioreactor design for enhanced stem cell proliferation and differentiation in tissue engineered constructs. Tissue Eng Part A 2008;14:802.

29. Aubin J. Regulation of osteoblast formation and function. Rev Endocr Metab Disord 2001;2:81-94. 